\title{
ESTUDO DO COMPORTAMENTO DOS LINFÓCITOS DERIVADOS DO TIMO EM PACIENTES COM PÊNFIGO FOLIÁCEO NA PRESENÇA DE LEVAMISOL
}

\author{
Maria Dolores Porto Acedo' a Lucyr Jones Antunes².
}

Foram estudados linfócitos $T$ de pacientes portadores de pênfigo foliáceo em relação à sua capacidade de formar rosáceas " $E$ ", diante de diferentes concentrações do imunopotenciador levamisol. O levamisol é uma substância que estimula formação de rosáceas de linfócitos $T$ ativos em individuos normais.

Os linfócitos de pacientes antes da corticoterapia sistêmica não responderam ao levamisol; já os linfócitos de pacientes em tratamento com corticóides tiveram inibida sua capacidade de formar rosáceas. Esses achados sugerem alteração no metabolismo celular dos linfócitos de pacientes penfigosos devido provavelmente a alguma falha no sistema enzimático dessas células envolvendo a fosfodiesterase do AMPc.

Palavras-chaves: Pênfigo foliáceo. Linfócitos. Corticosteróides. Levamisol.

O pênfigo foliáceo é uma dermatose que se caracteriza pelo aparecimento sucessivo de bolhas acantolíticas e eritrodermia esfoliativa ${ }^{13}$. É uma patologia de etiologia desconhecida embora o mecanismo auto-imune tenha sido sugerido por Beutner $\mathrm{e}$ cols $^{1-4}$ e Chorzelski ${ }^{6}$, quando descreveram a presença de auto-anticorpos dirigidos contra um antigeno do espaço intercelular do epitélio de doentes portadores de pênfigo foliáceo. Descreveram também que o título de anticorpos está relacionado com a atividade da doença, sugerindo uma participação ativa de anticorpos na formação das bolhas acantolíticas.

Os linfócitos timo-dependentes de pacientes portadores de pênfigo foliáceo foram quantificados por Reis e cols. ${ }^{11}$ que encontraram um valor diminuido quando comparado com o número de linfócitos de grupos controles e os autores sugeriram uma deficiência de imunidade celular nos pacientes penfigosos. Wybran e Fudenberg ${ }^{14}$ propuseram técnica capaz de pesquisar uma subpopulação de LT denominada linfócitos T ativos (LTa). Lay e cols ${ }^{9}$, Jondal e cols ${ }^{8}$ e Chisari e Edgington ${ }^{5}$ mostraram que a ligação entre

Trabalho do Laboratório de Imunologia do Anexo São Geraldo, Faculdade de Medicina, Universidade Federal de Minas Gerais, Belo Horizonte, MG.

1. Departamento de Biologia Geral, Instituto de Ciências Biológicas, Universidade Federal de Minas Gerais.

2. Departamento de Bioquímica e Imunologia, Instituto de Ciências Biológicas e Laboratório de Imunologia do Anexo São Geraldo, Universidade Federal de Minas Gerais.

Recebido para publicaçảo em 20-3-1980. linfócito $\mathrm{T}$ e hemácia de carneiro é um fenômeno dependente de temperatura, ions $\mathrm{Ca}^{++} \mathrm{e} \mathrm{Mg}^{++}, \mathrm{pH}$, nivel energético e da concentração intracelular de nucleotideos cíclicos.

No presente trabalho, procuramos avaliar o comportamento dos linfócitos $T$ ativos de pacientes portadores de pênfigo foliáceo, tratados com corticoterapia sistêmica e não tratados, quando postos em contato com substância estimuladora do GMPc, com o objetivo de verificar sua situação metabólica.

\section{MATERIAL E MÉTODOS}

Estudamos 20 individuos adultos normais, 24 pacientes portadores de pênfigo foliáceo em tratamento com corticosteróide e 11 pacientes com pênfigo foliáceo antes de se tratarem com corticosteróide.

Dez $\mathrm{ml}$ de sangue periférico foi retirado em seringas contendo $0,1 \mathrm{ml}$ de heparina (Glaxo, 5000 $\mathrm{U} / \mathrm{ml}$ ) e os linfócitos foram isolados em gradientes de "Ficoll-Hypaque" seguindo técnica de Thorsby e Bratlie $^{12}$.

Em uma série de tubos de hemólise foram colocados $0,1 \mathrm{ml}$ de diferentes concentrações $\left(10^{-4}\right.$, $10^{-6}, 10^{-8} \mathrm{M}$ ) de levamisol (Johnson \& Johnson) e $0,01 \mathrm{ml}$ da suspensão de linfócitos $\left(2 \times 10^{6} \mathrm{cels} / \mathrm{ml}\right)$. Os tubos foram incubados a $37{ }^{\circ} \mathrm{C}$ durante 15 minutos. Em seguida foi adicionado $0,15 \mathrm{ml}$ de hemácias de carneiro a $0,5 \%$ em solução de Dulbecco e a mistura foi centrifugada por 10 minutos a $1200 \mathrm{rpm}$. Linfócitos unidos a três ou mais hemácias foram consideradas como rosáceas. A viabilidade das células foi verificada 
Acedo MDP, Antunes LJ. Estudo do comportamento dos linfócitos derivados do timo em pacientes com pênfigo foliáceo na presença de levamisol. Revista da Sociedade Brasileira de Medicina Tropical 17: 27-30, Jan-Mar, 1984

utilizando o corante azul de tripan. Os linfócitos $\mathrm{T}$ totais desses pacientes foram quantificados seguindo técnica de Jondal e cols. ${ }^{8}$.

Para os testes nos quais foi verificado o efeito de diferentes tempos de incubação dos linfócitos diante do levamisol, a técnica utilizada foi a mesma descrita acima variando apenas o tempo de incubação a $37^{\circ} \mathrm{C}$.

\section{RESULTADOS E DISCUSSÃO}

A detecção de subpopulações de linfócitos no sangue periférico possibilitou o conhecimento da participação destas células em várias doenças. Wybran e Fudenberg ${ }^{14}$ mostraram que em processos patológicos como infecção viral e bacteriana, linfoma, leucemia linfática crônica e outros, ocorrem alterações na porcentagem de linfócitos timo-dependentes, tanto $\mathrm{T}$ ativos ( $\mathrm{LTa}$ ) quanto $\mathrm{T}$ total (LTt).

A determinação dos LTa e LTt em nossos pacientes tratados e em tratamento (Tabela 1) deixou claro a não alteração da capacidade dessas células formarem rosáceas com hemácias de carneiro, quando comparados aos linfócitos de indivíduos normais e de pacientes portadores de pênfigo foliáceo. Estes achados nos levaram a avaliar o estado funcional dos linfócitos de individuos normais e pacientes portadores de pênfigo foliáceo frente ao imunopotenciador levamisol.

Tabela 1 - Percentagem de linfócitos Tem individuos controles e pacientes portadores de pênfigo foliáceo, antese durante o tratamento com corticosteróides

\begin{tabular}{|c|c|c|c|c|c|c|c|c|}
\hline \multirow[t]{2}{*}{ Linfócitos $T$} & \multicolumn{2}{|c|}{ Controle $(n=20)$} & \multicolumn{2}{|c|}{$\begin{array}{l}\text { Pacientes não tratados } \\
\quad(n=11)\end{array}$} & \multirow[t]{2}{*}{ Significância * } & \multicolumn{2}{|c|}{$\begin{array}{l}\text { Pacientes em tratamento } \\
\qquad(n=24)\end{array}$} & \multirow[t]{2}{*}{ Significância * } \\
\hline & Variação & Média $\pm D P$ & Variação & Média $\pm D P$ & & Variação & Média $\pm D P$ & \\
\hline Ativo & $11-32$ & $23,0 \pm 5,5$ & $17,3-39,3$ & 10,2 & N & $4,7-38,0$ & $=10,3$ & $N$ \\
\hline Total & $38-65$ & $46,4 \pm 6,9$ & $29,4-58,4$ & $42,3 \pm 8,9$ & NS & $17,9-58,5$ & $35,9 \pm 8,6$ & $\mathrm{p}<0,01$ \\
\hline
\end{tabular}

* Teste $t$ "Student" $\quad \mathrm{DP}=$ desvio padrão

A Figura 1 mostra que a formação de rosáceas por LTa na presença de levamisol se encontra estimulada em individuos normais, semelhante ao descrito por Machado ${ }^{10}$. Observa-se também que os linfócitos dos pacientes portadores de pênfigo foliáceo se comportam de maneira diferente: aqueles doentes que não haviam sido tratados com corticóide tinham linfócitos que não apresentavam estimulo na formação de rosáceas, quando incubados com a droga. Os linfócitos dos pacientes em tratamento com corticóide apresentaram inibição na formação das rosáceas por LTa, após 15 minutos de incubação com levamisol. Esses dados sugerem que o tempo de incubação (15 min) poderia não ser o ideal para os linfócitos dos pacientes portadores de pênfigo foliáceo. Conseqüentemente a incubação de linfócitos de penfigosos por $15,30,45$ e $60 \mathrm{~min}$ foi comparada com a obtida com linfócitos de individuos normais.



Figura 1: Teste de estimulação de formação de rosácea " $E$ " 
Acedo MDP, Antunes $L J$. Estudo do comportamento dos linfócitos derivados do timo em pacientes com pénfigo foliáceo na presenca de levamisol. Revista da Sociedade Brasileira de Medicina Tropical 17: 27-30, Jan-Mar, 1984

A Figura 2 mostra o efeito da incubaçào dos linfócitos normais com o levamisol, em tempos variados. Observa-se que 15 min produz estimulação nas 4 concentrações utilizadas, fato que não ocorre nos outros diferentes tempos de incubação. Nos pacientes penfigosos (Figura 3), a incubação dos linfócitos com levamisol, nas diversas concentrações e em tempos diferentes, não induziu estimulação. Pudemos observar um fenômeno de inibição na formação das rosáceas.

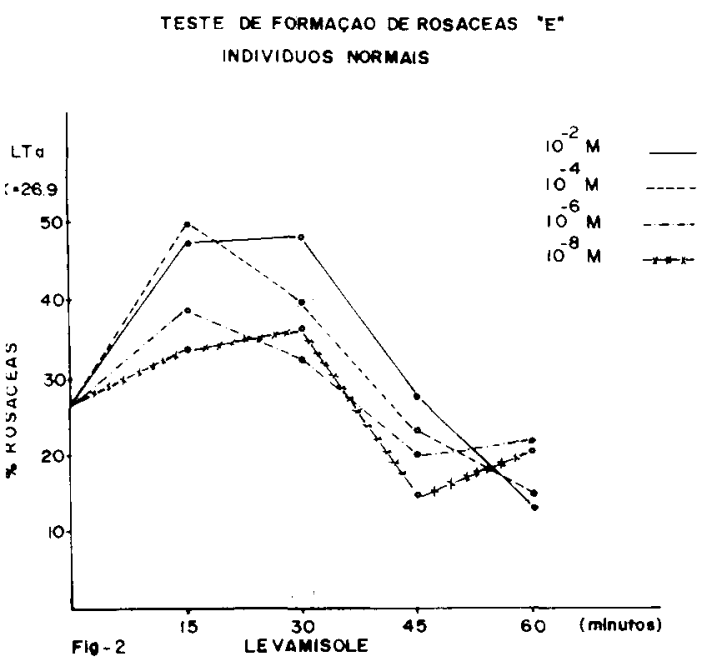

Figura 2: Teste de formação de rosáceas "E" indivíduos normais

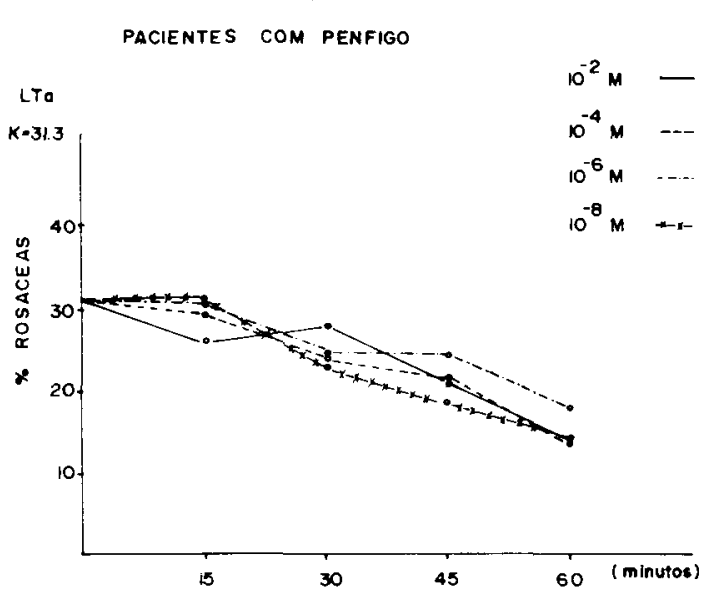

Fig- 3 LEVAMisOLE

Figura 3: Teste de formação de rosáceas "E" pacientes com pènfigo

Esses resultados sugerem a existência no linfócito de portadores de pênfigo foliáceo de uma alteração fisiológica e não de uma alteração qualitativa que pudesse ser corrigida com a incubação prolongada com levamisol e com a variação na concentração dessa droga.

Hadden e cols ${ }^{7}$ mostraram que o levamisol diminui a quantidade de $\mathrm{AMP}$ c intracelular e aumenta a quantidade de GMPc, resultando em aumento da atividade celular. Foi demonstrado através da formação das rosáceas na presença de levamisol que os linfócitos normais aumentam o percentual de rosáceas, enquanto que nos pacientes penfigosos não houve este aumento.

Nossos achados sugerem a existência de uma falha no sistema enzimático dos linfócitos envolvendo a fosfodiesterase do AMPc, causando uma alteração do metabolismo celular nos portadores de pênfigo foliáceo, explicando dessa maneira a baixa na capacidade de formar rosáceas com hemácias de carneiro em presença do levamisol.

\section{SUMMARY}

T lymphocytes from patients with Pemphigus foliaceus were studied fortheir ability to form $E$ rosettes in the presence of different concentrations of the immunostimulant levamisole. Lymphocytes from patients before systemic corticotherapy did not show stimulation when incubated with levamisole. Lymphocytes from patients submitted to corticotherapy had their ability to form rosettes inhibited. Those data suggest that the lymphocytes from patients with Pemphigus foliaceus may have some kind of defect in the phosphodiesterase of cyclic AMP.

Key words: Pemphigus foliaceus. Lymphocytes. Corticosteroid. Levamisole.

\section{REFERÊNCIAS BIBLIOGRÁFICAS}

1. Beutner EH, Jordon ER. Demonstration of skin antibodies in sera of pemphigus vulgaris patients by indirect immunofluorescent staining. Proceedings of the Society for Experimental Biology and Medicine 117: $505,1964$.

2. Beutner EH, Lever WF, Witebsky E, Jordon ER, Chertock B. Autoantibodies in pemphigus vulgaris. Journal of the American Medical Association 192: 682, 1965.

3. Beutner EH, Prigenzi SL, Hale W, Leme A, Bier OG. Immunofluorescent studies of autoantibodies to intercellular areas of epithelia in Brazilian pemphigus foliaceus. Proceedings of the Society for Experimental Biology and Medicine 127: 81, 1968. 
Acedo MDP, Antunes LJ. Estudo do comportamento dos linfócitos derivados do timo em pacientes com pênfigo foliáceo na presença de levamisol. Revista da Sociedade Brasileira de Medicina Tropical 17: 27-30, Jan-Mar, 1984

4. Beutner EH, Wood GW, Chorzelsky TP, Bier OG. Produção de lesões semelhantes às do pênfigo foliáceo pela injeção intradérmica em coelhos e macacos de soros de doentes com titulo elevado de auto-anticorpo. Memórias do Instituto Butantan 35: 79, 1971.

5. Chisari VF, Edgington ST. Human T lymphocyte "E" rosette function. A process modulated by intracellular cyclic AMP. Journal of Experimental Medicine 140: 1122,1974 .

6. Chorzelsky TP, Von Weiss JF, Lever WF. Clinical significance of autoantibodies in pemphigus. Archives of Dermatology 93: 570, 1966.

7. Hadden JW, Coffey RG, Hadden EM, Lopez-Corrales E, Sunchine GH. Effects of levamisole and imidazole on lymphocyte profiferation and cyclic nucleotide levels. Cellular Immunology 20: 98, 1975.

8. Jondal M, Holm G, Wigzell H. Surface markers on T and B lymphocytes forming autoimmune rosettes with sheep red blood cells. Journal of Experimental Medicine 136: 207,1972
9. Lay WH, Mendes NF, Bianco C, Nussenzweig V. Binding for sheep red blood cells to a large population of human lymphocytes. Nature 230: 531, 1971.

10. Machado JAN. Participação dos nucleotideos cíclicos AMP e GMP na regulação do fenômeno de formação de rosáceas " $E$ " em LTa. Tese de mestrado, Universidade Federal de Minas Gerais, Belo Horizonte, 1976.

11. Reis AP, Guerra HA, Guerra HVN. Linfócitos T e B em pênfigo foliáceo sul-americano. Revista da Associação Médica Brasileira 22: 285, 1976.

12. Thorsby $\mathbf{E}$, Bratlie A. A rapid method for preparation of pure lymphocyte suspensions. In: Terasaki PI (ed). Histocompatibility testing. Munksgard, Copenhagen, 1970 , p. 655,1970

13. Veronese R. Doenças infecciosas e parasitárias. 5 a ed., Guanabara Koogan, Rio de Janeiro, p. 960, 1972.

14. Wybran J, Fudenberg HH. Thymus-derived rosetteforming cells in various disease states: cancer, lymphoma, bacterial and viral infections, and other disease states. Journal of Clinical Investigation 52: 1026 1973. 